\title{
Users Empowered in Smart Grid Development? Assumptions and Up-To-Date Knowledge
}

\author{
Barbara van Mierlo \\ Wageningen University \& Research, Knowledge, Technology and Innovation, P.O. Box 8130, \\ 6700 EW Wageningen, The Netherlands; barbara.vanmierlo@wur.nl; Tel.: +31-317483258
}

Received: 19 November 2018; Accepted: 19 February 2019; Published: 26 February 2019

\begin{abstract}
Active involvement of users in smart grids is often seen as key to beneficial development of smart grids. In this paper, we investigate the diverse assumptions about how and why users should be active and to what extent these assumptions are supported by experiences in practice. We present the findings of a systematic literature review on four distinctive forms of user involvement in actual smart grid projects: demand shifting, energy saving, co-design, and co-provision. The state-of-the-art knowledge reflects the preoccupation with demand shifting in the actual smart grid development. Little is known about the other user roles. More diversity in types of projects regarding user roles would improve the knowledge base for important decisions defining the future of smart grids.
\end{abstract}

Keywords: smart grids; users; demand management; renewable energy transition

\section{Introduction}

Active involvement of users in smart grids is often seen as key to beneficial development of smart grids. This is signaled, among other things, by the abundant use of the term "prosumer" and similar terms, such as "co-provider", in the context of smart grids. It can also be seen in some of the definitions of smart grids that stress the role of users, such as the following: "A Smart Grid is an electricity network that can cost efficiently integrate the behaviour and actions of all users connected to it-generators, consumers and those that do both-in order to ensure economically efficient, sustainable power system with low losses and high levels of quality and security of supply and safety" [1] (p. 2).

Energy companies and policy institutions are developing methods to involve the users. The European Commission, for instance, pursues a so-called "user-centric" approach, involving an increased interest in electricity market opportunities, value added services, flexible demand for energy, lower prices, and microgeneration opportunities [2]. Scholars have emphasized the importance of active engagement of users, among other things, by stating that they should be an empowered part of the system [3]. It is expected that if users are empowered, smart grids may become an important element in climate change policy and the renewable energy transition.

Active involvement of users promoting smart grids is, however, not self-evident. Demonstrations against smart meters in the UK and the USA have shown that users have specific concerns and may actively resist smart developments [4]. In early accounts, several social scientists have warned against the dominant technological focus on the development of smart grids [5,6]. Wolsink [6] stated that smart grids may not further the deployment of distributed renewables due to a lack of understanding of how and why users would accept smart grids. He sketched two scenarios. In the first, groups of end users deploy renewable energy sources in microgrids and increase their autonomy in relation to central power suppliers. In this scenario, the common resources, i.e., the locally produced renewable electricity, are deployed optimally. In the second, grid operators gain power by increasing surveillance of domestic consumers and their energy consumption. In this scenario, demand regulation is the main driving force rather than the optimal use of renewable energy. This one may gain dominance as it 
fits better with dominant relationships in the energy sector and the common, centralized patterns of operating. An inventory of the first developments in practice, i.e., the application of smart grids in the first pilot projects, showed that social aspects have received little attention [7]. There is a strong engineering bias with a focus on new information and communication technologies (ICT), disregarding their interaction with other technological and social aspects of local energy systems. Moreover, economic rationales and automation are central elements of smart grid project designs, even though the projects vary considerably [8]. The roles and interactions of users with other stakeholders, market, and technology development should be evaluated for a solid understanding of smart grid development, especially in the residential sector [9].

There seems to be a contrast between the terminology implying active roles of users and the actual developments. As Schick [10] (p. 82) says, "Even though users play an important role in the imagination of experts, a gap remains between the experts and those who smart electricity infrastructures will come to affect". Apparently, different assumptions about how and why users should be involved in smart grid developments co-exist. This raises the questions of what these assumptions are and to what extent these are supported by the current experiences with smart grids in practice. As a first, crucial step to answering these questions, we define the state-of-the-art knowledge on these issues on the basis of a literature review.

In the following sections, we first present the research methodology. Subsequently, the results of the literature review are discussed with regard to four types of active user roles: demand shifting, energy saving, co-design, and co-provision. The paper ends with a discussion on important topics for further research and the implications of up-to-date knowledge for smart energy products and services (SEPS) as well as smart grid projects.

\section{Methodology}

In the past years, the early employment of smart grid in countries such as Denmark, the UK, and the Netherlands has been investigated in social scientific studies. These provide the foundation of the current knowledge about the roles of users and other stakeholders. The literature is scattered because most studies are (comparative) case studies, investigating one or two specific smart grid projects. As a consequence, an overview of the state-of-the-art knowledge is missing. In this paper, we present the findings of a systematic literature review, analyzing (1) the main assumptions regarding user involvement and (2) the lessons that can be derived about these assumptions from practice.

First, the scientific literature on user involvement in real-life smart grid developments was collected using the search term "smart grid" and synonyms thereof, such as "smart home", on the one hand and terms related to users on the other hand ("user", "prosumer", "customer", "consumer", "co-provider"). In this way, articles to be included in the analysis were selected from the web-based Google Scholar database. To find missing literature on community-led initiatives, we had a second round of search for "smart grids" in combination with "local energy initiatives" or related terms, such as "energy cooperative", "autonomy", "independence", and "micro-grid".

Secondly, to select the most relevant articles for the analysis, we screened the abstracts and methodology sections on the following criteria: (1) social scientific research, (2) peer-reviewed article in international journal, (3) relevant empirical evidence of actual experiences with smart grids, and (4) sound research methodology according to the standards in the diverse research domains. The resulting selection of articles was mostly about studies of smart grid pilot projects. Surveys among prospective users were included only if they provided additional insights. Ultimately, 43 studies were included in the analysis; some of these were studies were by the same authors.

Thirdly, the selected articles were roughly screened to see what the perspective on user involvement was. We classified types of user involvement in four distinct user roles.

Finally, the selected articles were organized by the four defined user roles, after which the findings and conclusions of the selected articles were qualitatively analyzed as secondary data. For each 
user role, the knowledge about the involvement of users in smart grids was synthesized as well as categorized on key topics. As a consequence, not all selected literature is mentioned in this paper.

The smart grid definition mentioned above stresses its technological characteristics and prioritizes cost-efficiency over other goals; it is even mentioned twice in the definition. Many other definitions emphasize digital technology and the communication through ICT-based devices. In our study, in order to develop a wide perspective on user roles, we followed a smart grid definition that includes the social features: "A smart grid is a socio-technical network characterized by the active management of both information and energy flows, in order to control practices of distributed generation, storage, consumption and flexible demand" [6] (p. 824).

The goals of the research were as follows:

1. To uncover the assumptions about user roles, motivations, responses, and energy behavior in scientific literature about smart grids and user involvement. What kind of involvement is considered key for which goals related to smart grids and with what argument?

2. To evaluate these assumptions in the light of the practice of smart grid development. To what extent are these assumptions confirmed in smart grid projects?

3. To evaluate the current knowledge. What is the state-of-the-art knowledge regarding the assumptions about user involvement in smart grids and what are the gaps therein?

4. To explore the implications of the findings for smart grid development. What conclusions can be derived from the findings for the need for further research and development of smart grids products, services, and projects?

\section{Results}

The assumptions about the roles of users differed throughout the literature depending on the key topic addressed. The topics were in turn often related to the specificities of the pilot project. The most important knowledge about each user role is presented herein by discussing the dominant assumptions and relating them to the key findings in recent empirical research.

\subsection{Demand Shifting}

The literature on the topic of flexibility in relation to smart grids ties in with the older debates on demand-side management. The key challenge is to match supply and demand better in order to accommodate the distributed energy sources and reduce $\mathrm{CO}_{2}$ emissions. Users are expected to respond to information about the availability of electricity or financial incentives, such as dynamic pricing, by shifting the energy load to preferred moments or a combination thereof. They tend to be addressed as isolated individuals making their own, autonomous decisions. The implicit assumption underlying information services is that new knowledge and awareness might motivate users to shift their energy use for environmental or financial reasons.

However, there were several examples of "disappointing" responses in the investigated projects. In the Jouw Energie Moment (Your Energy Moment) project, for instance, householders had requested for "smarting" their electrical heat pumps, but only four out of 38 actually switched it on [11].

Since 2014, several good social scientific studies have been conducted on demand shifting. Most of them related to what is called the "practice turn" in social sciences. The idea is that genuine interest in what moves people in their homes to consume energy helps to understand to what extent and under what conditions they may shift their energy consumption to other moments of the day.

A first insight is that domestic practices are pinned in time and place, related to relationships within the households, social conventions, and time structures of the activities of members of the households $[12,13]$. As a consequence, some practices are more prone to active time shifting than others. In general, cleaning practices (dishwashing, washing, and tumble drying) were found to be most suitable for demand-side response [14,15]. Practices implied in ambiance regulation, leisure, 
cooking, and eating, are less easy to change. Solitary tasks are easier to change than collective ones, such as family dining as well as practices that depend on the structure of activities outside the home.

Secondly, several authors confirmed that households have to "learn" to adapt their demand, i.e., change their practices and start seeing options for doing so $[8,12,16]$. In two projects investigated by Hansen [8], the knowledge about household consumption, electricity markets, prices, and electricity system loads had increased. There were, however, also accounts of what could be called "unlearning" the practices geared toward demand shifting. Kessels [16], for instance, showed that there was a "response fatigue" in one of the investigated projects in case of manual feedback and control.

Thirdly, flexibility interventions were seen to influence relationships among household members and to even have undesirable effects. Skjølsvold et al. [17] emphasized internal household dynamics between men and women. Drawing on two Norwegian smart grid demonstration projects, the provided feedback was found to "trigger" learning amongst eager men while alienating or excluding women.

Three key issues in relation to demand shifting were addressed in the literature: (1) automation and control, (2) financial incentives, and (3) feedback and communication.

(1) A key issue in demand shifting is the level of automation and control. Several authors emphasized that automation defines demand shifting more than economic incentives [8]. While earlier studies raised concerns about a loss of control, more recent studies provided another image [18,19]. In general, remote or automatic control seems to be acceptable to residents, that is, under conditions. It depends on what equipment is controlled, the information and security of smart techniques provided, and whether they have the ability to override the external control $[8,19]$. Results of a representative survey indicated that a direct load control tariff was more acceptable than the time-of-use tariffs presented [18]. The load control tariff gave residents a better sense of control over comfort, timing of activities, and spending as well as ease of use. The majority of respondents were inclined to accept direct load control if they would have the option to override it. Another study on actual projects showed similar results. The households involved did not mind having their heating devices (heat pumps and electric heating) remotely controlled, but they did not appreciate automatic charging of electric vehicles and automated control of other devices, such as freezers, fridges, and pumps [8].

Interestingly, even in the case of full automation, residents may show active engagement, for instance, by connecting extra devices to the system [8]. In general, however, active engagement by members of households is expected to involve only the anticipated responses to informational and financial incentives.

(2) Flexible network tariffs are based on the assumption that energy consumption is financially motivated. In an important study based on a meta-review of literature and an empirical validation in 32 European projects with user engagement, the following was concluded [16]:

- Time of use tariffs have more potential than dynamic tariffs (real-time [ricing), while the latter is more relevant in the case of local energy production.

- In order to work effectively, the dynamic tariff

- $\quad$ should be simple to understand for the end users,

- $\quad$ should have timely notifications of price changes, and

- $\quad$ should have a considerable effect on their energy bill.

If the tariff is more complex, the burden for the consumer could be eased by introducing automated control.

Whether dynamic tariffs will be accepted is most likely dependent on whether users consider them to be fair. A recent study [19] found that transport or capacity charges are considered fairer than peak pricing and much more than a flat rate. What is considered fair depends on noneconomic justification, guarantee that basic needs will be fulfilled, predictability, and being sure that peak use is not only affordable for rich people. 
Several studies indicated that there is seldom a linear relationship between financial incentives and energy consumption. This is explained by the intermediating role of domestic practices, as mentioned above. It also relates to the fact that considerations other than financial ones influence energy consumption. Saving energy, an interest in new techniques, and a green image are among the other reasons for becoming flexible $[5,19]$. If households are primarily motivated by a desire to become self-sufficient and autonomous, this could even create a tension with demand-side flexibility schemes, which tend to create new types of grid dependency (whether it be flexibility contracts, automated demand response, or market-based dynamic energy pricing incentives). In such cases, users may prefer to stick to established forms of "green engagement" with energy, such as green energy contracts and applying energy-efficient light bulbs [14].

(3) A recent study confirmed findings from earlier studies regarding the effectiveness of feedback provided [8]. Simple information and visualization methods, such as a light signal (green/red) and emails or text messages that integrate information about demand and its relationship with supply, tend to have a positive influence (see also [3]). Users evaluate them positively, understand the information, and tend to change their consumption patterns based on the input.

More complex interfaces provided ambiguous results. Web-based tools were used by less people: approximately 25\% in 11 Danish experiments [8]. Moreover, the satisfaction with the applicability of websites and advanced in-home boxes varied. Kendel [20] showed that if people are willing to visit a portal, more advanced information per appliance could slightly increase the effectiveness in flexibility.

It tends to be forgotten, however, that people's awareness of patterns of energy consumption is not only provided by direct, individual feedback. Naus [12] nicely showed how, in addition to individual learning, community interaction in the form of workshops and informal encounters with neighbors contributes to effective demand shifting.

In conclusion, it can be stated that the insights about demand shifting have considerably increased in the past years due to a large number of studies. It has been shown that there is certainly some room for triggering active responses from users, even though the relationship between incentive and energy consumption is mediated by practices and motives other than that intended with the measure. The findings of the studies provide some clear rules of thumb. However, whether and how measures for automation, financial incentives, and feedback mechanisms are effective depends ultimately on the specific features of the local energy system and the local setting, such as the relationships between residents and the project managers, conventions embedded in culture, weather conditions, etc. This was well illustrated in the comparative study by Bulkeley [21], which showed the outcomes of different settings and interventions. The first group of users had photovoltaic (PV) panels and a display showing their domestic consumption. This group was stimulated to do financial calculations of the revenues of possessing PV. The second group had PV and a device showing the moments of available electricity. The users were stimulated to change their routines of washing and dishwashing (modestly), among other things, by a timer on the washing machine. They were also engaged in energy management by checking weather forecasts. The third group was provided with PV and a water tank that automatically absorbs excess generation. This group started shifting their showering practices from the morning to the daytime or evening - a response that is rather surprising in the light of the social practices studies mentioned above.

\subsection{Energy Saving}

Smart grid systems are expected to stimulate residential users to save electricity. This expectation stems from two integrated smart grid developments. First, the diffusion of distributed renewable energy may trigger a motivation to save energy. Here, the mere possession of renewable energy technologies is assumed to trigger further behavioral change. A literature review reported that little is known about this effect [22]. While the installation of a PV system stimulates many households to reduce their overall electricity consumption according to themselves, the rare reports on actual consumption show otherwise, partly due to rebound effects. 
Secondly, smart meters are applied to provide residential users with regular information about their electricity consumption who hitherto lacked such insight. The related assumption is that energy consumption data, supplemented with, for instance, the related financial incentives, or a comparison with other households will stimulate a reduction in electricity consumption. The data provided with smart meters, however, are seldom the preferred and recommended real-time data.

For groups of users, energy saving seem to be quite important. Smale et al. [14], for instance, reported that not all discussants in the focus groups were convinced of the primacy of the time-shifting problem over other sustainability issues. Hansen and Borup [8] concluded on the basis of a comparison of 11 Danish experiments that other motivations are an interest in new energy technologies, being more environmentally friendly, and reducing the overall energy consumption.

Few studies have investigated energy saving in smart grid pilot projects. One of the exceptions is the Danish eFlex project. The study showed an overall reduction in electricity consumptions in response to the feedback from home energy management systems: "the 'control' household group, [with only the management system] ... had on average saved approximately $10 \%$ on their kilowatt hour consumption during the project period March 2011 to February 2012" [15].

While energy saving is of importance for specific user groups, it has received too little attention to arrive at conclusions about the relationship between smart grids and energy saving. A complicating factor is that the term "energy saving" has become ambiguous with the introduction of smart grids. Some researchers use it for demand shifting rather than reducing the overall energy consumption (see, for instance, [20]). Moreover, due to the electrification trend accompanying the smart grid development, just assessing increases or decreases in kilowatt hour consumption has little meaning. The meaning of, and aspirations regarding energy saving hence needs reviewing in the context of smart grids.

\subsection{Co-Design}

Many social scientists and some engineers critique the technological and economic rationality in the design of smart grid technologies and projects. Hansen et al. [8] (p. 260), for instance, stated: "Our analysis shows that the projects employ a technology driven approach to household users with a focus on testing ready-made technologies rather than on improving technologies by including consumers". For this reason, several scholars presuppose that if the smart grid technologies are co-designed, they will better address the users' needs [3,7]. There were some examples where future users were addressed with images or prototypes of potential products. However, we could not find any study on future users purposively and structurally being involved in the preparation phase of pilot projects.

That does not mean that users play no role at all in design processes. In the literature, we found several examples of projects in which the applied techniques or their applications were changed because of users' wishes and responses [15,19]. Hansen and Hauge [19] showed how, in a project in which 20 households were to be equipped with the same air/water heat pump, it was installed in only seven households. After a negotiation process, the other households instead received a hybrid air/water heat pump with a gas boiler installed, sunwells, or a geothermal heat pump.

It can be concluded that co-design is rare and has so far yielded little insights in the preferences of users. The documentation on interactions between users and project managers in the course of actual projects provides evidence that, at times, feedback from users does influence choices made in these projects. Allowing room for such forms of co-design during the use phase of projects may instigate a countervailing power against the misconceptions of leading engineers.

In general, it seems useful to think of co-design not at the level of products and services only but at the level of projects as well. In this way, socio-technological aspects regarding the local energy system and stakeholder relationships will be part of the negotiations rather than merely the interaction between residents and technology. 


\subsection{Co-Provision}

Where smart grids projects involve renewable energy, users are often regarded as co-providers. Instead of the passive consumer receiving energy, he/she is also producing and supplying energy. Such co-provision is regarded as an active role of users because their conduct "influences the grid and community, by reducing risks of load and voltage problems enabling more households to use PV" [21] (p. 17). Such perceptions of co-provision are merely technical; just the possession of renewable energy makes residents a provider. They are connected to the preoccupation with the flexibility dimension of smart grids. The related literature has been discussed above in the section "demand shifting".

A more radical perception is that of active, responsible citizens in the renewable energy transition process, where the relationships between the energy sector and users change drastically if users indeed take and get the responsibilities and power of being an energy provider. Transition advocates as well as several social scientists regard local energy initiatives (LEIs) to have the potential to transform the energy sector from fossil-fuel-based to renewable-energy-based by changing the relationships between citizens and institutional stakeholders. The related literature about LEIs forms a niche in the social scientific literature; smart grids are only touched upon as an issue. This may well mirror the priorities of the cooperatives.

A radical form of LEIs is the independent, local electricity systems. In microgrids or virtual power plants, prosumers may use, produce, and trade electricity without the interference of a central authority. The Brooklyn Microgrid is an example of an experiment in which energy is traded between prosumers and consumers. The grid operator has access to consumer data and manages energy use, loads, and demand response at negotiated rates. Quantitatively, the energy cooperatives do not yet contribute substantially. In the Netherlands, for instance, just $2 \%$ of the solar power installed was collectively owned in 2017 [23]. In this country, two cooperative energy suppliers organize 107 local energy initiatives, aiming to close the energy cycle. A study by Arentsen and Bellekom [24] illustrated that local energy associations often combine localized with centralized features, which is why the authors concluded that (p. 1) "local electricity initiatives can be considered a seedbed of innovation but with no potential to develop dominance in the electricity supply". Instead, the authors expected that the local initiatives will develop as niches inside the dominant electricity system, challenging its centrality and ever-increasing scale, and will add to the hybridization of its products and services. A dissimilar conclusion was drawn by Blanchet [25]. He studied the role of two LEIs in what he called the "remunicipalization" of Berlin's electricity grid and concluded that the (potential) impact of local initiatives on energy systems and their governance has been underestimated.

Unfortunately, there are few documented experiences with a truly active role of users as co-providers, probably due to demotivating policy. The findings are ambiguous regarding the potential of LEIs to change the energy system. Experiences in citizen-led initiatives may well provide very important insights on co-provision in addition to the industry- and government-led pilot projects that outnumber them.

\section{Discussion}

A need for user involvement in smart grids is often proclaimed. Users should be involved, among other things, for a good performance of smart grids, for the development of good SEPS, or a valuable contribution of this innovation to the renewable energy transition. The state-of-the-art knowledge on user involvement was identified here on the basis of a literature review of findings regarding four user roles.

Current knowledge predominantly concerns the user role of demand shifting. The results of the studies on this issue both confirm and contradict the assumptions about how users would respond to incentives. They provide some rules of thumb for triggering active responses. The results are somewhat scattered about subthemes due to the high diversity in energy systems in smart grid projects.

The studies steer away from the socio-psychological and economic theories that have dominated studies on energy users for decades. Sociological theories about social practices are shown to be 
fruitful to understand the complexity of changing practices involving energy use at the household or community level, especially regarding demand shifting.

On energy saving, the literature provides some limited dispersed knowledge. No valid conclusions regarding energy saving could be drawn. Nonetheless, it is a very important role in the eyes of users themselves and hence should be investigated further. Regarding co-design, it seems that users are hardly involved in the design of the technology and the projects, which means that knowledge on this type of involvement is lacking. Yet, there are indications of feedback loops from users to developers in running projects. Co-provision can be recognized in the emergence of LEIs. However, the findings on user involvement are ambiguous, and smart grids are not a priority of energy cooperatives.

An additional limitation of current research is that the relationships between users and stakeholders in the energy and other relevant sectors, such as ICT, are often disregarded. These relationships typically differ in the diverse pilot projects and influence user roles. Moreover, most studies that do focus on users do not investigate them in light of a wider renewable transition process and the role of smart grids therein. The question of whether and to what extent users are empowered remains unanswered. This may well be related to the optimism among smart grid advocates that smart grid transitioning itself guarantees a sustainable future.

Further empirical research evaluating the four user roles in current smart grid development is crucial. In such research, it is recommended to keep an open eye for unanticipated and unintended responses of users. This is very relevant in this early phase of smart grid introduction to society, which involves many uncertainties. Furthermore, it would be good to conduct further empirical research on standardization and smart grid policy and their influence on the decision-making process of the organizations initiating smart grid projects (particularly grid operators) and ultimately on user involvement.

A major implication of the findings for smart grid products and services is that they should take into account people's practices and relationships within the households and with their neighbors. Powells et al. [13] suggested to not only invent ways to let people be more flexible in the timing of their practices but to also reconfigure their practices in novel ways, especially those restricted by time constraints or social conventions. Slow cookers, for instance, would enable people to continue to eat together while shaving peak demand. Another proposed practice-aligned intervention is a launderette that uses stored, solar-heated hot water to clean clothes, which could provide services to both communities and those managing the distribution network.

The second implication is that the design and application of smart energy products and services should take place in an interactive process with (potential) users until there is sufficient evidence of what stimulates or hinders them to take on specific roles. Pilot projects as well as local energy initiatives provide the opportunity to regard SEPS not in an isolated way and users not as single, rational individuals but as part of a specific socio-technological system. Learning about smart grid development requires developing projects with a focus on local generation, local control, and cultural change in addition to the dominant projects aiming for enhanced efficiency and reliability. This would provide knowledge about the meaning of current socio-technological changes in the light of the contrasting future visions on smart grid development $[6,25]$, in short, knowledge about the pathways of change regarding smart grids and distributed renewable energy.

\section{Conclusions}

While expectations of user involvement in smart grids are high, ideas about what it is and for what reasons it is important are ambiguous. The four user roles provide clarity regarding the assumptions about different types of user involvement. Evaluation of these assumptions on the basis of existing empirical studies shows that current knowledge about user involvement in smart grid development predominantly relates to the role of demand shifting. Knowledge on the roles of energy saving, co-design, and co-provision is limited. 
The state-of-the-art knowledge exposes the preoccupation with demand shifting in the actual smart grid development. The expectations for user involvement reflected in terminology such as "empowered users" and "co-providers" is hardly mirrored in the practice of smart grid projects. More diversity in types of projects regarding user roles would improve the knowledge base for important decisions defining the future of smart grids.

Funding: This literature study is part of the interdisciplinary Co-Evolution of Smart Energy Product and Services (CESEPS) project. The project is funded in the framework of the joint programming initiative ERA-Net Smart Grids Plus, with support from the European Union's Horizon 2020 research and innovation programme.

Acknowledgments: I am grateful for the constructive comments of four anonymous reviewers. I also thank Esin Gültekin for the insightful discussions in the early preparation of this paper and Hilde Brouwers, Cihan Gercek, and Angèle Reinders for their feedback on the findings of the literature review.

Conflicts of Interest: The author declares no conflict of interest. The funders had no role in the design of the study; in the collection, analyses, or interpretation of data; in the writing of the manuscript; or in the decision to publish the results.

\section{References}

1. EC Directorate-General for Energy. Standardization Mandate to European Standardisation Organisations (ESOs) to Support European Smart Grid Deployment; M/490; European Commission: Brussels, Belgium, 2011.

2. European Technology Platform. Vision and Strategy for Europe's Electricity Networks of the Future; European Commission: Brussels, Belgium, 2006.

3. Obinna, U.P. Assessing Residential Smart Grids Pilot Projects, Products and Services: Insights from Stakeholders, End-Users from a Design Perspective; Delft University of Technology: Delft, The Netherlands, 2017.

4. Sovacool, B.K.; Kivimaa, P.; Hielscher, S.; Jenkins, K. Vulnerability and resistance in the United Kingdom's smart meter transition. Energy Policy 2017, 109, 767-781. [CrossRef]

5. Verbong, G.P.; Beemsterboer, S.; Sengers, F. Smart grids or smart users? Involving users in developing a low carbon electricity economy. Energy Policy 2013, 52, 117-125. [CrossRef]

6. Wolsink, M. The research agenda on social acceptance of distributed generation in smart grids: Renewable as common pool resources. Renew. Sustain. Energy Rev. 2012, 16, 822-835. [CrossRef]

7. Geelen, D.; Reinders, A.; Keyson, D. Empowering the end-user in smart grids: Recommendations for the design of products and services. Energy Policy 2013, 61, 151-161. [CrossRef]

8. Hansen, M.; Borup, M. Smart grids and households: How are household consumers represented in experimental projects? Technol. Anal. Strateg. Manag. 2018, 30, 255-267. [CrossRef]

9. Reinders, A.; Übermasser, S.; van Sark, W.; Gercek, C.; Schram, W.; Obinna, U.; Lehfuss, F.; van Mierlo, B.; Robledo, C.; van Wijk, A. An exploration of the three-layer model including stakeholders, markets and technologies for assessments of residential smart grids. Appl. Sci. 2018, 8, 2363. [CrossRef]

10. Schick, L.; Winthereik, B.R. Innovating Relations-or Why Smart Grid is not too Complex for the Public. Sci. Technol. Stud. 2013, 26, 82-102.

11. Kobus, C.B.; Klaassen, E.A.M.; Mugge, R.; Schoormans, J.P.L. A real-life assessment on the effect of smart appliances for shifting households' electricity demand. Appl. Energy 2015, 147, 335-343. [CrossRef]

12. Naus, J.; van der Horst, H.M. Accomplishing information and change in a smart grid pilot: Linking domestic practices with policy interventions. Environ. Plan. C Politics Space 2017, 35, 379-396. [CrossRef]

13. Powells, G.; Bulkeley, H.; Bell, S.; Judson, E. Peak electricity demand and the flexibility of everyday life. Geoforum 2014, 55, 43-52. [CrossRef]

14. Smale, R.; van Vliet, B.; Spaargaren, G. When social practices meet smart grids: Flexibility, grid management, and domestic consumption in The Netherlands. Energy Res. Soc. Sci. 2017, 34, 132-140. [CrossRef]

15. Nyborg, S.; Røpke, I. Constructing Users in the Smart Grid-Insights from the Danish eFlex Project. Energy Effic. 2013, 6, 655-670. [CrossRef]

16. Kessels, K.; Kraan, C.; Karg, L.; Maggiore, S.; Valkering, P.; Laes, E. Fostering residential demand response through dynamic pricing schemes: A behavioural review of smart grid pilots in Europe. Sustainability 2016, 8, 929. [CrossRef] 
17. Skjølsvold, T.M.; Jørgensen, S.; Ryghaug, M. Users, design and the role of feedback technologies in the Norwegian energy transition: An empirical study and some radical challenges. Energy Res. Soc. Sci. 2017, 25, 1-8. [CrossRef]

18. Fell, M.J.; Shipworth, D.; Huebner, G.M.; Elwell, C.A. Public acceptability of domestic demand-side response in Great Britain: The role of automation and direct load control. Energy Res. Soc. Sci. 2015, 9, $72-84$. [CrossRef]

19. Hansen, M.; Hauge, B. Scripting, control, and privacy in domestic smart grid technologies: Insights from a Danish pilot study. Energy Res. Soc. Sci. 2017, 25, 112-123. [CrossRef]

20. Kendel, A.; Lazaric, N.; Maréchal, K. What do people 'learn by looking'at direct feedback on their energy consumption? Results of a field study in Southern France. Energy Policy 2017, 108, 593-605. [CrossRef]

21. Bulkeley, H.; Powells, G.; Bell, S. Smart grids and the constitution of solar electricity conduct. Environ. Plan. A 2016, 48, 7-23. [CrossRef]

22. van Mierlo, B. People's Involvement in Residential PV and their Experiences. In Photovoltaic Solar Energy: From Fundamentals to Applications; Reinders, A., Verlinden, P., Freundlich, A., Eds.; John Wiley \& Sons, Ltd.: Hoboken, NJ, USA, 2017; pp. 634-645.

23. Hier Opgewekt. Lokale Energiemonitor 2017 [Local Energy Monitor 2017]; Hier Opgewekt: Utrecht, The Netherlands, 2017.

24. Arentsen, M.; Bellekom, S. Power to the people: Local energy initiatives as seedbeds of innovation? Energy Sustain. Soc. 2014, 4, 1-12. [CrossRef]

25. Blanchet, T. Struggle over energy transition in Berlin: How do grassroots initiatives affect local energy policy-making? Energy Policy 2015, 78, 246-254. [CrossRef]

(C) 2019 by the author. Licensee MDPI, Basel, Switzerland. This article is an open access article distributed under the terms and conditions of the Creative Commons Attribution (CC BY) license (http:/ / creativecommons.org/licenses/by/4.0/). 